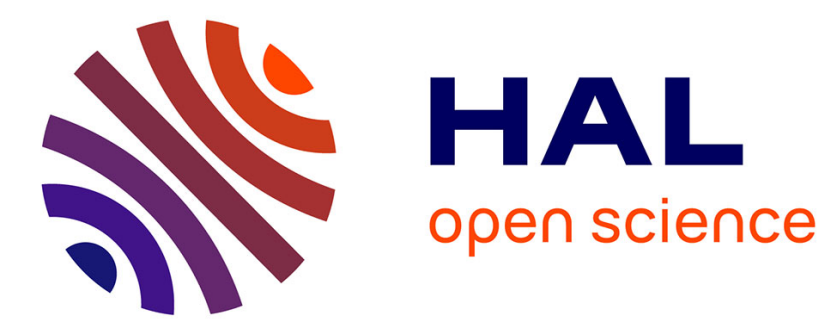

\title{
Increased gonadotropin levels in goldfish do not result in alterations in circulating thyroid hormone levels
}

\author{
D.S. Mackenzie, M. Sokolowska, R.E. Peter, Bernard Breton
}

\section{To cite this version:}

D.S. Mackenzie, M. Sokolowska, R.E. Peter, Bernard Breton. Increased gonadotropin levels in goldfish do not result in alterations in circulating thyroid hormone levels. General and Comparative Endocrinology, 1987, 67, pp.202-213. 10.1016/0016-6480(87)90149-3 . hal-02728153

\section{HAL Id: hal-02728153 \\ https://hal.inrae.fr/hal-02728153}

Submitted on 2 Jun 2020

HAL is a multi-disciplinary open access archive for the deposit and dissemination of scientific research documents, whether they are published or not. The documents may come from teaching and research institutions in France or abroad, or from public or private research centers.
L'archive ouverte pluridisciplinaire HAL, est destinée au dépôt et à la diffusion de documents scientifiques de niveau recherche, publiés ou non, émanant des établissements d'enseignement et de recherche français ou étrangers, des laboratoires publics ou privés. 


\title{
Increased Gonadotropin Levels in Goldfish Do Not Result in Alterations in Circulating Thyroid Hormone Levels
}

\author{
Duncan S. Mackenzie, M. Sokolowska, ${ }^{*}$ R. E. Peter, ${ }^{*}$ and Bernard Breton $\dagger$ \\ Department of Biology, Texas A\&M University, College Station, Texas 77843, *Department of Zoology, \\ University of Alberta, Edmonton, Alberta, Canada T6G 2E9, and †Laboratoire de Physiologie des Poissons, \\ INRA, Campus de Beaulieu, F35024 Rennes, Cedex, France
}

Accepted March 17, 1987

\begin{abstract}
To determine whether increases in gonadotropin levels are capable of altering thyroid function in goldfish, plasma thyroid hormone levels were measured following induced changes in endogenous gonadotropin secretion and injection of carp gonadotropin. Radiofrequency lesions placed in the nucleus preopticus periventricularis or monosodium-L-glutamate-induced lesions of the posterior nucleus lateralis tuberis (NLT) of the hypothalamus were capable of stimulating significant increases in plasma gonadotropin levels, but were without effect on plasma triiodothyronine $\left(\mathrm{T}_{3}\right)$ or thyroxine $\left(\mathrm{T}_{4}\right)$ at time intervals ranging from $5 \mathrm{hr}$ to 10 days. Likewise, injections of a superactive analog of gonadotropin-releasing hormone resulted in profound increases in gonadotropin levels without associated changes in thyroid hormones. No changes in the circulating levels of $T_{4}$ or $T_{3}$ were observed in response to injection of purified carp gonadotropins whereas injection of bovine thyrotropin or carp pituitary extracts stimulated significant increases in $\mathrm{T}_{4}$. Radiofrequency lesions of the pituitary stalk or of the anterior NLT also resulted in significant increases in circulating levels of $T_{4}$, but not of $T_{3}$, at 10 and $30 \mathrm{hr}$ postlesion. These results demonstrate that direct acute stimulation of circulating thyroid hormone levels is not an intrinsic action of endogenous goldfish gonadotropin and that activation of the reproductive system, leading to ovulation in some cases, is without effect on blood total thyroid hormone levels. Additionally, these results confirm that hypothalamic inhibition of the pituitary-thyroid axis exists in this teleost fish and demonstrate that interruption of this inhibition results in a time-dependent, high-magnitude increase in circulating thyroxine levels. 1987 Academic Press, Inc.
\end{abstract}

Although extensive evidence exists for a fundamental relationship between reproduction and thyroid function in teleost fishes (see reviews by Eales, 1979; Leatherland, 1982), the exact nature of the hormonal interactions between these two systems remains obscure. A number of experimental studies have indicated that this interaction may be due to the ability of hormones secreted by one system to modify the activity of the other. In particular, several studies have demonstrated that reproductive hormones can stimulate thyroid activity. Thus, exogenously administered pituitary gonadotropins have been shown to stimulate the thyroid gland in several teleost species (Fontaine, 1969; Milne and Leatherland, 1980; MacKenzie, 1982;
Chakraborti et al., 1983; Brown et al., 1985), indicating that gonadotropins, either directly or through their actions on the gonads, can act in a thyrotropic capacity in teleosts. However, the physiological significance of this thyrotropic action of gonadotropins remains unclear due to the possible contamination of gonadotropin preparations with thyrotropin (Donaldson and McBride, 1974) and the fact that gonadotropins used for these studies are heterologous in origin and may thus express nonphysiological, "heterothyrotropic" actions when injected into heterologous species (Fontaine, 1969; MacKenzie, 1982; MacKenzie and Licht, 1984). Few studies of gonadotropin actions on the teleost thyroid have used homologous hormones or have 
examined the thyroid response to quantified increases in endogenous gonadotropin. Although work in Fundulus (Brown et al., 1985) has shown that stimulation of reproductive activity, and presumably of endogenous gonadotropin, by mammalian gonadotropin-releasing hormone is not accompanied by increased thyroxine levels, there is at present only one study (Stacey et al., 1984) in which circulating thyroid hormone levels in a teleost have been directly related to changes in endogenous gonadotropin release during a period of reproductive activation. To understand the role of gonadotropins in regulating thyroid function, it is therefore necessary to examine thyroid activity in a species in which homologous gonadotropins are available for testing, and in which techniques are available to induce and measure changes in circulating levels of endogenous gonadotropins.

The objective of the present study was to examine a commonly used indicator of thyroid stimulation, plasma thyroid hormone levels, during induced increases in endogenous gonadotropin levels in a common model teleost species, the goldfish Carassius auratus. Techniques for stimulation of endogenous gonadotropin release exist for this species (reviewed in Peter, 1983), and the availability of a specific radioimmunoassay for carp gonadotropin (Peter et al., 1984a) makes it possible to quantify the time course of endogenous changes in gonadotropin levels. Additionally, preparations of homologous gonadotropins are available for injection. Thus, the goldfish provides an excellent species in which to examine the effects of endogenous and exogenous gonadotropins on thyroid function and to examine the time course of changes in thyroid activation during quantified changes in endogenous gonadotropin levels.

\section{MATERIALS AND METHODS}

Fish. Goldfish (common or comet variety) were purchased from Grassyforks Fisheries (Martinsville,
IN), at different times of the year and maintained in 250 -liter flow-through aquaria for 2 to 12 weeks at simulated natural photoperiod and temperature. Fish were acclimated to specific experiments as described below. All fish were fed an excess of EWOS trout food once daily (between 1000 and $1200 \mathrm{hr}$ ) before and during experiments, and weighed $20-35 \mathrm{~g}$ when used. For all experiments reported in this paper, fish were anesthetized in $50 \mathrm{mg} / \mathrm{liter} \mathrm{MS}-222$ (ethyl- $m$-aminobenzoate, Sigma Chemical Co.) prior to blood sampling. Blood samples were removed from the caudal vasculature using a heparinized syringe, and plasma was subsequently separated, frozen, and stored at $-30^{\circ}$ for radioimmunoassay.

Hypothalamic lesioning. Radiofrequency lesions were placed in discrete locations in the hypothalamus using the technique of Peter and Gill (1975). Briefly, following 3 weeks of acclimation animals were anesthetized, weighed, and a dental drill was used to open a bone flap in the parietal bone to expose the dorsal surface of the brain. Fish were then clamped into a stereotaxic apparatus (Peter and Gill, 1975) and the lesion electrode, consisting of a size 0 insect pin insulated except for $0.5 \mathrm{~mm}$ at the tip, was zeroed to the anterior midmargin of the posterior commisure. The electrode was then moved to stereotaxic coordinates for the anterior-ventral nucleus preopticus periventicularis (NPP) or anterior ventral nucleus lateralis tuberis (NLT) (Peter and Gill, 1975). Current (70-90 $\mathrm{mV}$ ) was applied from a Grass LM4 lesion-maker for $30 \mathrm{sec}$. The electrode was then removed, the bone flap sewn in place, and the fish returned to their tanks. Sham fish had the electrode placed in the hypothalamus without current applied. Additionally, an untreated group of fish was bled during lesioning to provide initial controls. At the time intervals given under Results, sham and lesioned animals were anesthetized and blood was sampled from the caudal vasculature into a heparinized, $1-\mathrm{ml}$ syringe. At the termination of each experiment, fish were bled, decapitated, and sexed, and body and gonad weights were determined. The brain and cranium for each fish were fixed in Bouin's fluid, decalcified, and embedded in paraffin; selected brains were serially sectioned to confirm lesion locations. Sexually mature female fish acclimated to $20^{\circ}, 16 \mathrm{~L}: 8 \mathrm{D}$ in May and sexually regressed, mixedsex fish acclimated to $25^{\circ}, 16 \mathrm{~L}: 8 \mathrm{D}$ in August were used for NPP lesion studies (Peter and Paulencu, 1980). Sexually regressed male and female fish acclimated to $26^{\circ}, 16 \mathrm{~L}: 8 \mathrm{D}$ in September were used for NLT lesion studies. At the termination of the NLT-lesioning experiment ( 3 weeks), half of the fish in the sham and experimental groups received an injection of bovine TSH (NIAMDD-bTSH-9, 21.1 IU/mg) at a dose of $2 \mathrm{mU} / \mathrm{g}$ body wt and were bled again $4 \mathrm{hr}$ later.

NLT lesions were also produced using the monosodium glutamate technique (Peter et al., 1980). Mixedsex goldfish in early stages of gonadal recrudescence 
acclimated to $12^{\circ}, 12 \mathrm{~L}: 12 \mathrm{D}$ in November and sexually regressed, mixed-sex fish acclimated to $26^{\circ}, 16 \mathrm{~L}: 8 \mathrm{D}$ in September were given a single injection of L-glutamic acid, sodium salt (Sigma Chemical Co.) at a dose of $2.5 \mathrm{mg} / \mathrm{g}$ body wt. Fish were serially blood sampled following injection at intervals given under Results, and half received a final TSH injection as described above at the termination of the experiment.

Injection studies. Female goldfish in late stages of ovarian recrudescence were injected with combinations of a superactive synthetic luteinizing hormonereleasing hormone analog, des-Gly ${ }^{10}\left[\mathrm{dAla}^{6}\right] \mathrm{LHRH}$ ethylamide (LHRHa, Sigma Chemical Co.) in combination with the dopamine antagonist pimozide (a gift from Janssen Pharmaceuticals, Ltd., Beerse, Belgium), using a two-injection protocol (fish depicted in Fig. 3 of Sokolowska et al., 1985). Fish were acclimated to experimental temperatures $\left(12\right.$ or $\left.20^{\circ}\right)$ and 16L:8D for 4-7 days prior to injection. They received initial intraperitoneal injections of pimozide (dose $=$ $10 \mu \mathrm{g} / \mathrm{g}$ body wt) or pimozide vehicle (acidified $0.7 \%$ $\mathrm{NaCl}+0.1 \%$ sodium metabisulfite) followed $3 \mathrm{hr}$ later by a second ip injection of LHRHa $(0.1 \mu \mathrm{g} / \mathrm{g}$ body wt) or LHRHa vehicle (acidified fish physiological saline). Plasma was serially sampled using the time protocol under Results.

Response of goldfish to injection of exogenous gonadotropins was evaluated using a technique similar to the thyrotropin bioassay described in MacKenzie (1982). Goldfish were obtained in the summer and held at $22^{\circ}$ in flow-through tanks. Fish were sexually regressed when received and remained so during the experimental period; no attempt was made to sex animals prior to hormone injection. Forty-eight hours prior to injection, fish were netted from the stock tank, anesthetized, weighed, and fin clipped for identification. Fish were then transferred in groups of six to 80-liter aerated tanks and acclimated to $22^{\circ}$ for 48 hr. Preliminary studies indicated that a dose-dependent increase in thyroxine $\left(\mathrm{T}_{4}\right)$ levels could be stimulated by bovine thyrotropin (bTSH) at doses of 1 and $10 \mathrm{mU} / \mathrm{g}$ body wt using a protocol in which fish received a single bTSH injection; following this injection, plasma $T_{4}$ levels were significantly elevated over levels in saline-injected (control) fish at $3 \mathrm{hr}$, reached maximum levels at $6 \mathrm{hr}$, and declined at $9 \mathrm{hr}$. Levels in fish receiving $10 \mathrm{mU}$ bTSH/g body wt were still elevated above control levels at $26 \mathrm{hr}$. A bioassay protocol was therefore developed in which fish received a single hormone injection and were blood sampled $5 \mathrm{hr}$ later. This protocol gave a linear dose-response for bTSH at doses ranging from 0.06 to $4 \mathrm{mU} / \mathrm{g}$ body wt. All assays included at least three doses of the bovine TSH standard, NIAMDD-bTSH-9 (21.1 IU/mg), obtained from the National Pituitary Agency of the National Institutes of Health. Carp pituitary fractions were prepared using established techniques (Breton, 1981; Peter et al., 1983) and were as follows: a nongly- coprotein pituitary extract representing the component of carp pituitary homogenate which did not bind to concanavalin A Sepharose (corresponding to the Con-AI fraction of Idler and $\mathrm{Ng}, 1983$ ); a partially purified carp $\mathrm{GtH}$, comprising material which was adsorbed to Con-A Sepharose (Con-AII) and was further purified to a fraction of molecular weight range from 20,000 to $35,000 \mathrm{Da}$ on Ultrogel ACA 54; and three highly purified carp GtHs resulting from subsequent ion-exchange chromatography of partially purified carp gonadotropins (as above) followed by final ACA 54 chromatography. One of these partially purified GtHs, 378, is the standard and antigen for the GtH RIA described below. The other two, 34 and 39, were prepared from prior GtH purifications. Gonadotropic activity of these GtH preparations was estimated using an in vivo trout oocyte maturation bioassay (Jalabert et al., 1974) with a purified salmon GtH as standard (Breton, 1981); the partially purified carp GtH had $50 \%$ of the activity of the salmon GtH, whereas the purified carp GtHs ranged in activity from 130 to $170 \%$ as active as the standard.

Radioimmunoassays and statistics. Total $\mathrm{T}_{4}$ was measured using the radioimmunoassay (RIA) technique of Mackenzie et al. (1978). Total triiodothyronine $\left(T_{3}\right)$ was measured using an RIA protocol identical to that for $\mathrm{T}_{4}$, but using $\mathrm{T}_{3} \operatorname{tracer}(1200 \mu \mathrm{Ci} / \mu \mathrm{g}$, New England Nuclear Corp.), $T_{3}$ standards (Sigma Chemical Co.), and $\mathrm{T}_{3}$ antiserum (40\% binding at a final dilution of 1:15,000, cross reaction with $\mathrm{T}_{4}$ less than $1 \%$; prepared by Dr. V. Kruse, Copenhagen, Denmark). An identical series of high-, medium-, and low-range internal standard plasmas was included in all $\mathrm{T}_{3}$ and $\mathrm{T}_{4}$ assays. In 12 assays, means $\pm \mathrm{SE}$ were $67.4 \pm 1.9,15.0 \pm 0.7$, and $0.43 \pm 0.04 \mathrm{ng} / \mathrm{ml}$, respectively, for the $\mathrm{T}_{4}$ standards and $3.9 \pm 0.3,2.1 \pm 0.08$, and $1.6 \pm 0.2 \mathrm{ng} / \mathrm{ml}$, respectively, for the $\mathrm{T}_{3}$ standards. Intra-assay coefficients of variation, based on triplicate determinations of potencies from serial dilutions of three standards in 4 separate assays, were less than 7\% for all standards. Maturational (Con-AII) gonadotropin was measured using a homologous carp GtH (Peter et al., 1984a) RIA. Means ( $\bar{x}$ ), standard errors (SE), analysis of variance, and Duncan's multiple range test or Mann-Whitney $U$ test for significance were performed using the SPSS program package. Significance level was set at $\alpha=0.05$. Bioassay potencies were calculated using the computer program BIOPROG obtained from the Biomedical Computing Technology Information Center, Vanderbilt Medical Center (Nashville, TN).

\section{RESULTS}

\section{Hypothalamic Lesions}

Lesioned fish appeared healthy and resumed feeding within $24 \mathrm{hr}$ of surgery. In 
all lesion experiments, final weights taken at the termination of the experiment did not differ significantly from initial weights prior to lesioning. Results of NPP lesions in mature females (mean GSI $\pm \mathrm{SE}=14.2 \pm$ $1.1 \%$ ) are shown in Table 1 . No significant changes were detected in the levels of either thyroid hormone following sham or lesion treatments (an apparent increase in $\mathrm{T}_{4}$ at $10 \mathrm{hr}$ in lesioned fish was due to high levels in one individual and was not significant). A significant increase in GtH occurred at 5 to $48 \mathrm{hr}$. Similar results were obtained for regressed fish (data not shown); a significant increase in $\mathrm{GtH}$ found at 24 and $48 \mathrm{hr}$ was not accompanied by any significant changes in $\mathrm{T}_{4}$ levels (sufficient plasma was not available for $\mathrm{T}_{3}$ determination in regressed fish). Additionally, no sex-related $\mathrm{T}_{4}$ differences were apparent. By contrast, radiofrequency lesions placed in the NLT region of the hypothalamus were capable of inducing a rapid significant increase in $T_{4}$ in both males and females (Figs. 1 and 2) over levels in shamlesioned controls. Mean $\mathrm{T}_{4}$ levels returned to control values within 1 week, although some individual fish maintained high levels at this time. All fish had returned to control levels by 2 weeks, where they remained at 3 weeks. Three hours after injection of bovine $\mathrm{TSH}$, an equivalent significant in-
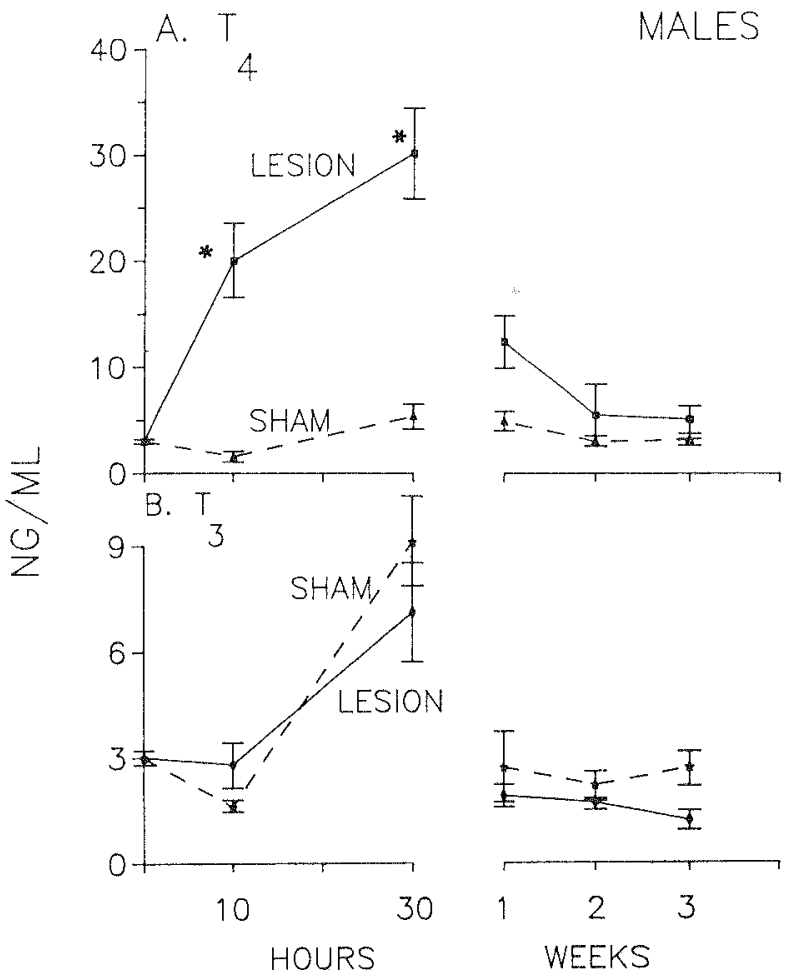

FIG. 1. Levels of $T_{4}(A)$ and $T_{3}(B)$ in the plasma of male goldfish following placement of radiofrequency lesions (solid lines) or sham lesions (broken lines) in the nucleus lateralis tuberis. ${ }^{*}$ Levels which are significantly greater than those in sham-lesioned controls at the same time.

crease in $T_{4}$ levels occurred in sham and lesioned fish of both sexes $(\bar{x} \pm \mathrm{SE}=69.6$. \pm 11.8 for lesioned fish and $57.4 \pm 5.7$ for shams, $N=5$ males and 5 females for each treatment). A third group of animals in which lesions were placed in the hypothal-

TABLE 1

Effects of NPP Lesions on Plasma Gonadotropin (GtH), $\mathrm{T}_{3}$, And $\mathrm{T}_{4}$ Levels in Mature FEMALE GOLDFISH

\begin{tabular}{lccccr}
\hline \multirow{2}{*}{ Treatment } & Time after lesion & & \multicolumn{3}{c}{ Hormone $^{a}$} \\
\cline { 4 - 6 }$(\mathrm{hr})$ & $N$ & $\mathrm{~T}_{3}$ & $\mathrm{~T}_{4}$ & \multicolumn{1}{c}{$\mathrm{GtH}$} \\
\hline \multirow{2}{*}{ Sham } & 5 & 7 & $2.1 \pm 0.7$ & $0.7 \pm 0.2$ & $2.5 \pm 0.6$ \\
& 10 & 7 & $1.3 \pm 0.4$ & $0.7 \pm 0.3$ & $3.2 \pm 0.4$ \\
& 24 & 6 & $1.7 \pm 0.3$ & $0.6 \pm 0.3$ & $21.0 \pm 9.9$ \\
Lesion & 48 & 6 & $1.4 \pm 0.6$ & $0.4 \pm 0.2$ & $2.7 \pm 0.4$ \\
& 5 & 7 & $1.9 \pm 0.6$ & $0.6 \pm 0.2$ & $22.9 \pm 6.4^{*}$ \\
& 10 & 6 & $1.4 \pm 0.4$ & $1.3 \pm 0.6$ & $66.6 \pm 29.4^{*}$ \\
& 24 & 7 & $1.6 \pm 0.6$ & $0.6 \pm 0.3$ & $133.1 \pm 51.2^{*}$ \\
& 48 & 6 & $2.2 \pm 0.6$ & $0.7 \pm 0.3$ & $227.7 \pm 46.6^{*}$
\end{tabular}

* Significantly greater than sham-operated controls at the same sample time.

$a$ Values are means $(\mathrm{ng} / \mathrm{ml}) \pm \mathrm{SE}$. 


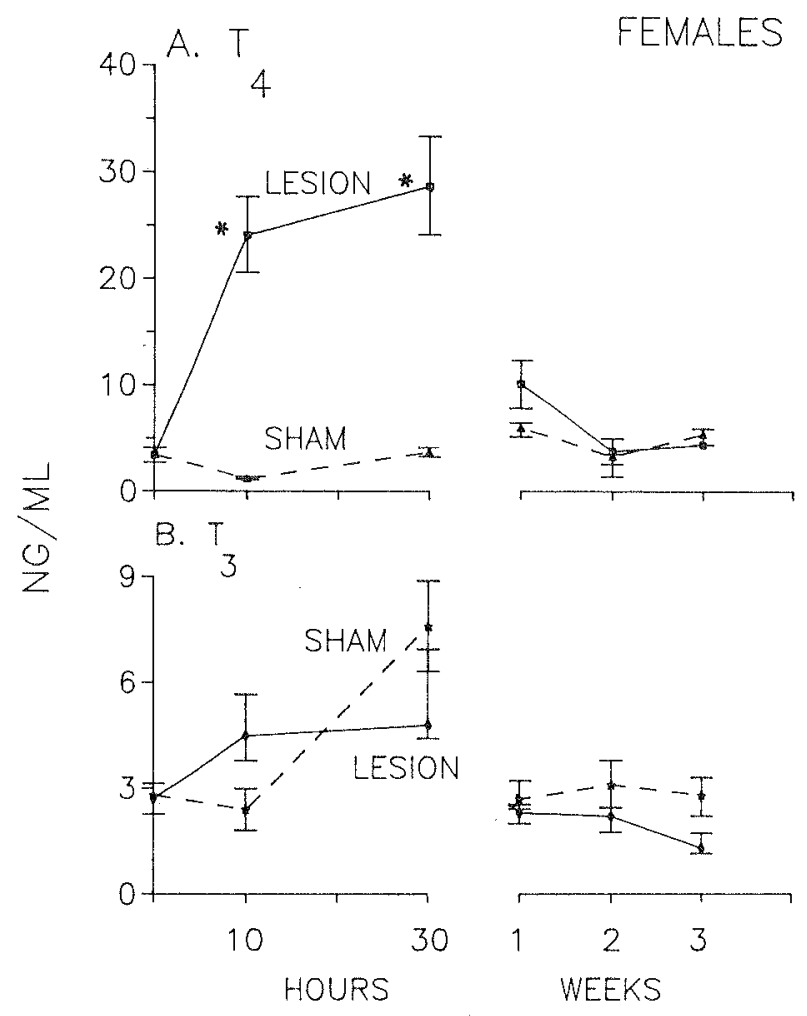

Frg. 2. Levels of $\mathrm{T}_{4}(\mathrm{~A})$ and $\mathrm{T}_{3}(\mathrm{~B})$ in the plasma of female goldfish following placement of radiofrequency lesions (solid lines) or sham lesions (broken lines) in the nucleus lateralis tuberis. ${ }^{*}$ Levels which are significantly greater than those in sham-lesioned controls at the same time.

amus but in which no $\mathrm{T}_{4}$ response was evident at 10 or $30 \mathrm{hr}(N=4-8$ for both sexes) did not differ significantly from controls at any time. Histological examination of brains of NLT-lesioned fish with high $\mathrm{T}_{4}$ levels showed damage in portions of the anterior NLT and/or pituitary stalk. $\mathrm{T}_{3}$ levels in NLT-lesioned fish with high $\mathrm{T}_{4}$ levels were not significantly different from those in sham controls at any time. Gonadotropin levels in NLT-lesioned fish were variable. Animals in which the pituitary stalk was damaged or destroyed had GtH levels ranging from 15 to $200 \mathrm{ng} / \mathrm{ml}(N=12)$ at 10 and $30 \mathrm{hr}$, compared with 2.6 to $0.5 \mathrm{ng} / \mathrm{ml}$ in sham controls $(n=8)$. GtH levels returned to control values in these fish by 1 week and remained there until termination of the experiment. These high $\mathrm{GtH}$ animals also showed significant increases in plasma $T_{4}$ levels. However, six animals in which parts of the anterior NLT were destroyed but in which the stalk remained intact showed elevated $\mathrm{T}_{4}$ levels without increases in $\mathrm{GtH}$.

The response to monosodium-L-glutamate injections is shown in Table 2. Both males and females were in early to mid stages of gonadal recrudescence (male GSI $=2.6 \pm 0.4 \%$; female GSI $=4.6 \pm 0.6 \%$ ) . No significant difference in any endocrine response was detected between sexes, and so animals were grouped by treatment for analysis. A significant increase in $\mathrm{GtH}$ was found at 10 and $30 \mathrm{hr}$ in MSG-injected animals; levels in these animals dropped to control values at 5 and 10 days. No change in $T_{3}$ or $T_{4}$ levels was detected in either MSG or control animals at any time. Exogenous bovine TSH was, however, able to stimulate a significant, equivalent increase in $\mathrm{T}_{4}$ in both control and MSG-treated fish after 10 days. In two subsequent experiments (data not shown) performed in regressed and gravid females, MSG was again without effect on $\mathrm{T}_{4}$ levels at 21 and 30 days.

In all experiments, control levels of $\mathrm{T}_{3}$ remained relatively stable, between 0.5 and $3 \mathrm{ng} / \mathrm{ml}$. Significant increases in $\mathrm{T}_{3}$ were noted following surgery in both lesioned and sham fish, indicating a possible effect of stress on plasma levels of this hormone as had been noted in other teleosts (Eales, 1985). As in other fish (e.g., Stacey et al., 1984), $T_{4}$ levels were more variable between samplings. This variation in $\mathrm{T}_{4}$ did not appear to be related to size, reproductive state, or acclimation history of the fish.

LHRHalpimozide injections. The timecourse characteristics of the hormonal response to LHRHa and pimozide injections at $20^{\circ}$ are given in Table 3. Pimozide and LHRHa, alone or in combination, were able to stimulate significant increases in GtH which were apparent starting at $6 \mathrm{hr}$ and were maintained at least until $48 \mathrm{hr}$ (Sokolowska et al., 1985). No changes in $\mathrm{T}_{3}$ or $\mathrm{T}_{4}$ levels were found at any time for any treatment. Fish acclimated to $12^{\circ}$ 
TABLE 2

Plasma LeVels of GtH, $\mathrm{T}_{3}$, AND $\mathrm{T}_{4}$ IN GOLdFISH FOLLOWING INJECTIONS OF MSG

\begin{tabular}{|c|c|c|c|c|}
\hline \multirow[b]{2}{*}{ Hormone and time } & \multicolumn{2}{|c|}{ Saline injected } & \multicolumn{2}{|c|}{ MSG injected } \\
\hline & $N$ & Response $^{a}$ & $N$ & Response $^{a}$ \\
\hline \multicolumn{5}{|l|}{$\mathrm{GtH}$} \\
\hline $10 \mathrm{hr}$ & 8 & $8.8 \pm 0.7$ & 16 & $16.9 \pm 4.3^{*}$ \\
\hline $30 \mathrm{hr}$ & 8 & $6.2 \pm 0.9$ & 16 & $15.2 \pm 2.9^{*}$ \\
\hline 5 days & 8 & $6.1 \pm 1.0$ & 16 & $9.0 \pm 1.9$ \\
\hline 10 days & 8 & $6.0 \pm 0.8$ & 16 & $7.9 \pm 0.7$ \\
\hline \multicolumn{5}{|l|}{$\mathrm{T}_{3}$} \\
\hline $10 \mathrm{hr}$ & 8 & $2.2 \pm 0.2$ & 15 & $1.3 \pm 0.2$ \\
\hline $30 \mathrm{hr}$ & 8 & $0.9 \pm 0.1$ & 16 & $0.6 \pm 0.1$ \\
\hline 5 days & 8 & $2.2 \pm 0.3$ & 15 & $2.0 \pm 0.2$ \\
\hline 10 days & 7 & $1.9 \pm 0.2$ & 13 & $2.2 \pm 0.3$ \\
\hline 10 days, $3 \mathrm{hr}$ TSH & 4 & $2.4 \pm 0.3$ & 7 & $2.6 \pm 0.3$ \\
\hline \multicolumn{5}{|l|}{$\mathrm{T}_{4}$} \\
\hline $10 \mathrm{hr}$ & 7 & $0.7 \pm 0.2$ & 16 & $1.0 \pm 0.3$ \\
\hline $30 \mathrm{hr}$ & 8 & $0.2 \pm 0.1$ & 16 & $0.8 \pm 0.2$ \\
\hline 5 days & 8 & $0.3 \pm 0.1$ & 15 & $0.3 \pm 0.1$ \\
\hline 10 days & 7 & $0.3 \pm 0.1$ & 13 & $0.6 \pm 0.1$ \\
\hline 10 days, $3 \mathrm{hr}$ TSH & 4 & $12.2 \pm 1.7^{* *}$ & 7 & $14.4 \pm 5.5^{* *}$ \\
\hline
\end{tabular}

* Significantly greater than saline injected at the same sample time.

** Significantly greater than same animals prior to TSH injection.

${ }^{a}$ Values are means $(\mathrm{ng} / \mathrm{ml}) \pm \mathrm{SE}$.

showed a similar change in GtH levels in response to LHRHa and pimozide again without any accompanying changes in thyroid hormone levels (data not shown). Thyroid hormone levels in subsequent experiments were also not influenced by lower doses of pimozide $(0.1$ and $1.0 \mu \mathrm{g} / \mathrm{g}$ at 48 $\mathrm{hr}$ ), longer time intervals (up to $72 \mathrm{hr}$ ), or ovulatory state (experiments in which all pimozide- or LHRHa-injected animals ovulated still showed no difference in thyroid hormone levels between ovulated fish and controls), even though all these experimental treatments resulted in significant $\mathrm{GtH}$ increases.

Pituitary hormone injection. Figure 3 shows the $\mathrm{T}_{4}$ release response of goldfish to a series of doses of bovine TSH standard, partially purified carp gonadotropin, and a Con-AI carp pituitary extract. Both carp preparations were capable of stimulating significant increases in $\mathrm{T}_{4}$ release over saline-injected controls which were parallel to the lower two doses of the bTSH standard. Calculated potency estimates for the carp preparations relative to the bovine TSH were 0.12 (95\% confidence limits (c.l.) $=0.051-0.261$, equivalent to $2.5 \mathrm{IU}$ TSH activity/mg) for the partially purified carp $\mathrm{GtH}$ and 0.02 (95\% c.1. $=0.008-0.044$, equivalent to $0.4 \mathrm{IU} \mathrm{TSH}$ activity $/ \mathrm{mg}$ ) for the Con-AI preparation. No significant changes in plasma $T_{3}$ were found in any of the hormone-injected groups. The three carp gonadotropins tested were without effect on $\mathrm{T}_{4}$ release (Fig. 4). Because only limited quantities of carp gonadotropins were available, they could not be tested at high doses. At the doses tested, these fractions represent less than 0.25 IU TSH activity/mg.

\section{DISCUSSION}

The objective of the present study was to determine whether acute increases in endogenous gonadotropin levels result in stimulation of the thyroid gland in a model fish species in which the time course of 
Hormone $^{a}$

\begin{tabular}{|c|c|c|c|c|c|}
\hline \multirow[b]{2}{*}{ Treatment and sample time } & \multirow[b]{2}{*}{$N$} & \multirow[b]{2}{*}{$N$ ovulated } & & & \\
\hline & & & $\mathrm{T}_{3}$ & $\mathrm{~T}_{4}$ & $\mathrm{GtH}$ \\
\hline \multicolumn{6}{|l|}{ Vehicle + saline } \\
\hline $6 \mathrm{hr}$ & 7 & 0 & $1.7 \pm 0.2$ & $6.9 \pm 0.7$ & $7.9 \pm 1.2$ \\
\hline $24 \mathrm{hr}$ & 7 & 0 & $2.2 \pm 0.1$ & $5.4 \pm 0.3$ & $6.9 \pm 1.2$ \\
\hline $48 \mathrm{hr}$ & 7 & 0 & $2.7 \pm 0.4$ & $6.4 \pm 0.5$ & $3.3 \pm 1.1$ \\
\hline \multicolumn{6}{|l|}{ Pimozide + saline } \\
\hline $6 \mathrm{hr}$ & 6 & 0 & $1.4 \pm 0.2$ & $7.1 \pm 1.1$ & $137.5 \pm 63.1^{*}$ \\
\hline $24 \mathrm{hr}$ & 6 & 2 & $1.5 \pm 0.2$ & $6.4 \pm 0.6$ & $144.3 \pm 62.4^{*}$ \\
\hline $48 \mathrm{hr}$ & 6 & 0 & $2.1 \pm 0.3$ & $7.2 \pm 0.4$ & $15.8 \pm 7.5^{*}$ \\
\hline \multicolumn{6}{|l|}{ Vehicle + LHRHa } \\
\hline $6 \mathrm{hr}$ & 7 & 0 & $2.0 \pm 0.3$ & $6.6 \pm 0.6$ & $191.7 \pm 75.8^{*}$ \\
\hline $24 \mathrm{hr}$ & 7 & 1 & $1.8 \pm 0.2$ & $5.4 \pm 0.4$ & $107.0 \pm 32.5^{*}$ \\
\hline $48 \mathrm{hr}$ & 7 & 1 & $1.9 \pm 0.2$ & $5.9 \pm 0.2$ & $4.3 \pm 1.4$ \\
\hline \multicolumn{6}{|l|}{ Pimozide + LHRHa } \\
\hline $6 \mathrm{hr}$ & 7 & 0 & $1.3 \pm 1.0$ & $6.8 \pm 0.6$ & $632.7 \pm 173.6^{*}$ \\
\hline $24 \mathrm{hr}$ & 7 & 3 & $1.5 \pm 0.2$ & $5.5 \pm 0.5$ & $399.9 \pm 89.0^{*}$ \\
\hline $48 \mathrm{hr}$ & 7 & 3 & $1.6 \pm 0.1$ & $6.5 \pm 0.4$ & $24.4 \pm 6.7^{*}$ \\
\hline
\end{tabular}

* Significantly greater than vehicle/saline groups as same time.

a All values in means $(\mathrm{ng} / \mathrm{ml}) \pm \mathrm{SE}$.

changes in $\mathrm{GtH}$ and thyroid hormone levels can be quantified accurately. Three techniques (radiofrequency lesioning, chemical lesioning with monosodium glutamate, and injection of gonadotropin-releasing hormone) were used to stimulate increases in endogenous $\mathrm{GtH}$ levels in goldfish representing a variety of reproductive states (varying from regressed to fully developed)

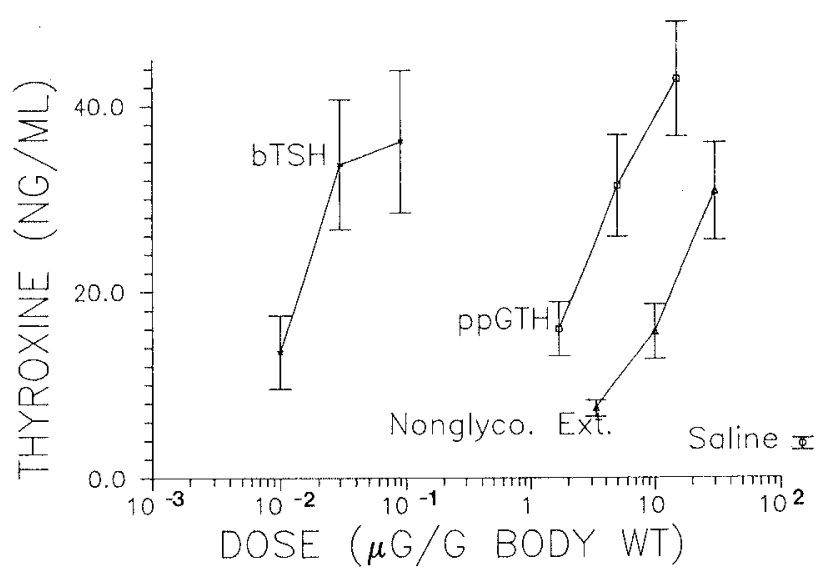

FrG. 3. Thyroxine-release response of goldfish to increasing doses of bovine TSH (bTSH), partially purified carp gonadotropin (ppGtH), and a nonglycoprotein extract of carp pituitaries (Nonglyco. Ext.). and acclimation conditions. Although all of these techniques resulted in significant stimulation of $\mathrm{GtH}$ release, none resulted in an elevation of $T_{4}$ or $T_{3}$ above levels in controls at times ranging from $5 \mathrm{hr}$ to 3 weeks after treatment. By contrast, hypothalamic lesions destroying all or part of the area thought to be responsible for the secretion of thyrotropin-inhibiting factor

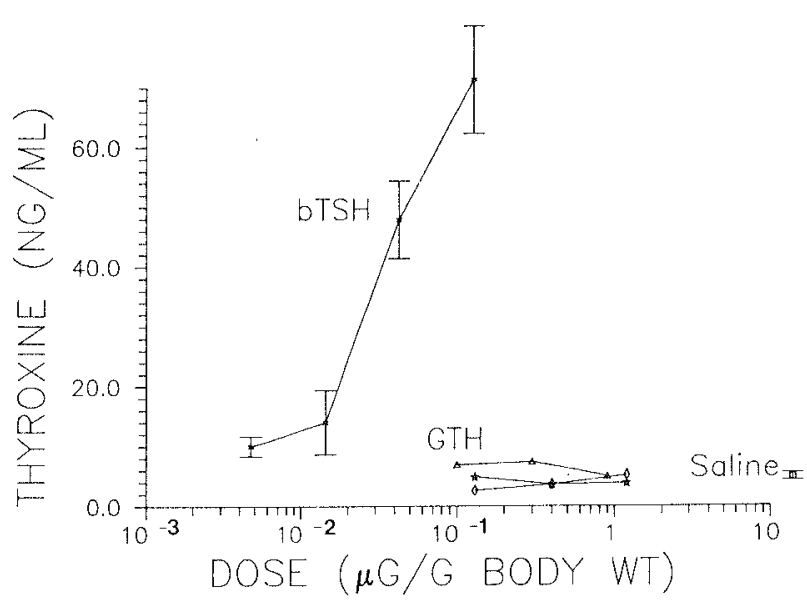

FIG. 4. Thyroxine-release response of goldfish to increasing doses of bovine TSH (bTSH) and three purified carp $\mathrm{GtH}$ fractions. 
(TIF) (Peter and McKeown, 1975) stimulated an acute increase in plasma thyroxine levels. The goldfish thyroid is thus capable of exhibiting an acute, high-magnitude thyroxine release response to stimulation which can be maintained for at least 10 to $30 \mathrm{hr}$. As this corresponds to the period of time during which significant $\mathrm{GtH}$ increases were stimulated, we conclude that acute increases in endogenous $\mathrm{GtH}$ do not stimulate $T_{4}$ secretion in sexually mature or regressed goldfish.

In addition to examining the response of goldfish to endogenous $\mathrm{GtH}$ increases, the present study also presents data indicating that the goldfish thyroid is unresponsive to exogenously administered gonadotropins. Carp pituitary extracts stimulate a dose-dependent increase in circulating $\mathrm{T}_{4}$ parallel to that stimulated by bovine thyrotropin. This activity is presumably due to thyrotropin contamination of the extracts, as final $\mathrm{GtH}$ fractions following ion exchange chromatography and gel filtration lack thyrotropic activity. Although limited quantities of carp gonadotropins made it impossible to test very high doses for accurate potency estimates, these carp preparations were still less than $1 \%$ as active as the bovine TSH standard and less than $10 \%$ as active as partially purified gonadotropin in stimulating $\mathrm{T}_{4}$ release.

In a recent review which included a consideration of the interactions between reproduction and thyroid function in teleost fishes, Leatherland (1982) concluded that it is likely thyroid activity is stimulated by increased activity of the pituitary-gonad axis in teleosts, especially during the late stages of gonadal growth. This represents a time at which rapid and profound changes are occurring in the secretion of hypophysiotropins, gonadotropins, and gonadal steroids (Peter, 1981, 1983; Fostier et al., 1983), implicating these hormones as an important part of any thyroid-reproductive link. Results of the present study and the findings of Brown et al. (1985) in Fundulus indicate, however, that the neurohormones controlling $\mathrm{GtH}$ release in teleosts, GnRH and dopamine (Peter, 1983), are without effect on plasma $T_{4}$ levels. Additionally, the present study demonstrates that acute increases in both endogenous and exogenous gonadotropins do not result in significant increases in circulating $\mathrm{T}_{4}$, indicating that they are incapable of stimulating the thyroid directly, as heterologous gonadotropins appear to be capable of doing (MacKenzie and Licht, 1984). In several cases, these GtH increases were stimulated in animals in the later stages of gonadal development, confirming previous field studies (Stacey et al., 1984) which demonstrated no increases in thyroid hormone levels associated with ovulatory $\mathrm{GtH}$ surges in white suckers. The thyrotropic actions of heterologous gonadotropins may consequently be due to their ability to stimulate endogenous gonadal steroid secretion. Tetrapod gonadotropins have been shown to stimulate the secretion of estradiol, testosterone, and progesterone from teleost ovaries in vitro (Yaron and Barton, 1980; Bona-Gallo and Licht, 1983; Kagawa et al., 1984). Additionally, castration has been shown to lower plasma thyroid hormone levels or thyroid activity in perch and catfish; these levels can subsequently be restored or stimulated over precastration levels by steroid but not gonadotropin injection, indicating that thyrotropic activity of gonadotropins is mediated through steroid release (Chakraborti et al., 1983; Jamaluddin et al., 1983). Although sufficient plasma was not available for steroid hormone measurement in the present study, the increases in GtH induced by our treatments almost certainly resulted in increases in circulating endogenous steroids in maturing or mature females as Kagawa and Nagahama (unpublished results cited in Kagawa et al., 1983), Stacey et al. (1984), Kagawa et al. (1984), and Peter et al. (1984b) all have found significant increases in circulating progestins, estradiol, 
and testosterone associated with spontaneous or gonadotropin- and brain lesion-induced ovulation in goldfish. In spite of the profound activation of the pituitary-gonad axis induced by several treatments in the present study, in some cases leading to induced ovulation and its subsequent steroid alterations, no change in circulating thyroxine levels was found. Although the possibility remains that endocrine changes associated with long-term reproductive activation as occur during the prolonged period of gonadal growth in most temperate teleosts may influence circulating thyroid hormone levels, we conclude that homologous gonadotropins are without effect, either direct or indirect, on circulating thyroid hormone levels in regressed or sexually mature goldfish, thus indicating that goldfish can distinguish between homologous gonadotropins and thyrotropins.

The increase in $\mathrm{T}_{4}$ levels caused by radiofrequency lesions placed in the ventral, basal hypothalamus (the anterior NLT) confirms that inhibitory hypothalamic control exists over thyroid function in goldfish (Peter and Mckeown, 1975; Ball, 1981). Previous studies have demonstrated that activation of the thyroid system in vivo occurred at 1 to 12 weeks after interruption of hypothalamic inhibitory control (Peter, 1970; Grau and Stetson, 1977; Pickford et al., 1981), whereas the present study demonstrates that hypothalamic lesioning results in a rapid (within $10 \mathrm{hr}$ ) and high-magnitude increase in plasma $\mathrm{T}_{4}$. Interestingly, high thyroxine levels are not maintained for more than several days, even though histological examination at 3 weeks indicated that permanent destruction of brain nuclei had been induced in lesioned fish. The low levels of thyroxine found at 1 to 3 weeks in lesioned fish in the present experiment do not appear to be due to desensitization of the thyroid to stimulation, as exogenous bovine TSH stimulates equivalent increases in circulating $\mathrm{T}_{4}$ in lesioned and sham-lesioned fish. Peter (1970) demon- strated that lesions placed in the NLT or pituitary stalk region of goldfish under conditions equivalent to those in the present study resulted in significantly increased thyroid epithelial cell height and radioiodine uptake at 30 days postlesion; thus, stimulation of the thyroid appears to be maintained for at least this long. A possible explanation for the decline in thyroxine levels is an adjustment in the peripheral kinetics of thyroid hormones (Eales, 1985). In salmonids, it has been demonstrated that the thyroxine degradation rate is increased under conditions of chronic stimulation of thyroxine secretion, resulting in lower plasma thyroxine levels through increased $\mathrm{T}_{4}$ turnover in the blood (Eales et al., 1982; Specker et al., 1984). Since $\mathrm{T}_{4}$ turnover rates in the blood were not examined in the present study, it is possible that experimental manipulations resulted in coordinated changes in $\mathrm{T}_{4}$ secretion and degradation which were not reflected by total thyroxine levels (Eales, 1985). The significant increase in circulating $\mathrm{T}_{4}$ found following NLT lesions indicates, however, that acute stimulation of $\mathrm{T}_{4}$ secretion can be detected in goldfish within $48 \mathrm{hr}$ (equivalent to the time period during which acute $\mathrm{GtH}$ increases occurred), and that compensatory changes in kinetics take longer than this amount of time.

The present study was not intended to describe the areas of the NLT directly involved in the production of TIF, as NLT lesions were used primarily as a technique to examine the magnitude and time course of thyroxine-release response to brain lesioning. Cursory examination of sections from selected brains indicated that effective lesions were localized in the NLT-pituitary stalk area, previously proposed by Peter (1970) as the area of inhibitory control over thyroid function. Lesions throughout the preoptic area were ineffective, as were MSG-induced lesions. MSG has been shown to cause cell hypertrophy and edema from the anterior margin of the 
pituitary stalk to the posterior margin of the NLT, presumably destroying cell bodies but not axons in these areas (Peter et al., 1980). Maximum hypertrophy occurs at $24 \mathrm{hr}$ with necrosis of cell bodies well developed by 8 days. In the present study, as in previous work (Peter et al., 1980), MSG injection elicited transient increases in circulating GtH. No $\mathrm{T}_{4}$ response to $\mathrm{MSG}$ injection was found, indicating that cells of the mid- to posterior NLT are not involved in inhibitory control of $\mathrm{TSH}$ secretion, contrary in part to the conclusion by Peter (1970) that the anterior, mid-, and posterior NLT together are the source of TIF. Again, this lack of $\mathrm{T}_{4}$ response does not appear to be due to thyroid insensitivity, as bovine TSH elicited equivalent $\mathrm{T}_{4}$ release responses in both MSG-injected and control fish. Several fish were examined in which increases in both $\mathrm{T}_{4}$ and $\mathrm{GtH}$ occurred in response to lesions in the vicinity of the NLT. In all of these fish, minor to extensive damage to the pituitary stalk had occurred. Pituitary stalk lesions have been shown to lead to increased release of $\mathrm{GtH}$, presumably due to interruption of inhibitory hypothalamic control of $\mathrm{GtH}$ secretion at the pituitary (Peter and Paulencu, 1980).

Although the exact chemical nature of TIF has not been elucidated, a number of neurotransmitters and peptides present in the teleost brain and CSF have been implicated in inhibition of TSH release (Peter and McKeown, 1975). Dopamine has been proposed to play a role in the inhibition of TSH secretion in teleosts, as destruction of dopaminergic neurons by intracranial injection of 6-hydroxydopamine in Fundulus resulted in increased circulating $\mathrm{T}_{4}$ levels at 2 weeks postinjection (Grau and Stetson, 1978). In the present study, a potent dopamine antagonist, pimozide, did not influence plasma $\mathrm{T}_{4}$ levels when injected intraperitoneally, although it was very effective in stimulating $\mathrm{GtH}$ release or enhancing the $\mathrm{GtH}$ release response to GnRH stimulation. In goldfish, pimozide acts outside the brain by blocking tonic dopaminergic inhibition of GtH secretion at the pituitary (Peter et al., 1986). Thus, given that effective doses of pimozide are reaching the pituitary gland, and given the rapid $\mathrm{T}_{4}$ increase observed when inhibitory control of thyroid activity is interrupted (as with NLT lesions), we conclude that dopamine is probably not the TIF at the pituitary level in goldfish. Dopamine may, however, be involved in modulation of TSH secretion through actions in higher centers of the brain, as it is in mammals (Morley, 1981). Several neuroactive chemicals have also been proposed to function as thyrotropinreleasing hormones in teleosts (Peter and McKeown, 1975; Ball, 1981). In the present study, $\mathrm{T}_{4}$ levels were too low in all animals undergoing lesioning to detect any possible decreases, and no $\mathrm{T}_{4}$ decreases were observed in animals in injection experiments.

In summary, the present study demonstrates that although hypothalamic lesions and injections of bovine TSH or carp pituitary extracts are capable of stimulating a significant increase in circulating $\mathrm{T}_{4}$ levels in goldfish, hypothalamic lesions or hypophysiotropin injections which result in increases in circulating gonadotropin or injections of homologous gonadotropins do not influence circulating thyroid hormone levels. In contrast to the extensive literature showing thyrotropic or heterothyrotropic actions of heterologous gonadotropins in teleost fishes (Fontaine, 1969; Chakraborti et al., 1983; MacKenzie and Licht, 1984; Brown et al., 1985), it is apparent that the goldfish thyroid is not responsive to acute increases in endogenous gonadotropins.

\section{ACKNOWLEDGMENTS}

We thank Carol Nahorniak for her technical assistance and the National Hormone and Pituitary Program for its supply of bovine TSH. This work was supported by an Alberta Heritage Foundation for Medical Research Postdoctoral Fellowship and funds from NOAA via the Texas A\&M University Sea Grant Program, Project R/M-27, to D.S.M., and Grant 
A6371 from the National Science and Engineering Research Council of Canada to R.E.P.

\section{REFERENCES}

Ball, J. N. (1981). Hypothalamic control of the pars distalis in fishes, amphibians, and reptiles. Gen. Comp. Endocrinol. 44, 135-170.

Bona-Gallo A., and Licht, P. (1983). Specificity to gonadotropins in the response of in vitro estrogen secretion by fish ovaries. Gen. Comp. Endocrinol. 51, 316-319.

Breton, B. (1981). A study of salmon (Oncorhynchus tschawytscha) pituitary hormone dissociation. Gen. Comp. Endocrinol. 45, 147-152.

Brown, C., Grau, E. G., and Stetson, M. (1985). Functional specificity of gonadotropin and thyrotropin in Fundulus heteroclitus. Gen. Comp. Endocrinol. 58, 252-258.

Chakraborti, P., Rakshit, D., and Bhattacharya, S. (1983). Influence of season, gonadotropins, and gonadal hormones on the thyroid activity of freshwater perch, Anabas testudineus (Bloch). Canad. J. Zool. 61, 359-364.

Donaldson, E., and McBride, J. (1974). Effect of $\mathrm{ACTH}$ and salmon gonadotropin on interrenal and thyroid activity of gonadectomized adult sockeye salmon. J. Fish. Res. Board Canada 31, 1211-1214.

Eales, J. (1979). Thyroid functions in cyclostomes and fishes. In "Hormones and Evolution" (E. J. W. Barrington, Ed.), Vol. 1, pp. 341-436. Academic Press, New York.

Eales, J. G. (1985). The peripheral metabolism of thyroid hormones and regulation of thyroidal status in poikilotherms. Canad. J. Zool. 63, 1217-1231.

Eales, J., Chang, J., Van Der Kraak, G., Omeljaniuk, R., and Uin, L. (1982). Effects of temperature on plasma thyroxine and iodide kinetics in rainbow trout, Salmo gairdneri. Gen. Comp. Endocrinol. 47, 295-307.

Fontaine, Y.-A. (1969). La specificite zoologique des proteines hypophysaires capables de stimuler la thyroide. Acta Endocrinol. Suppl. 136, 1-154.

Fostier, A., Jalabert, B., Billard, R., Breton, B., and Zohar, Y. (1983). The gonadal steroids. In "Fish Physiology"' (W. S. Hoar, D. J. Randall, and E. M. Donaldson, Eds.), Vol. 9, Part A, pp. 277-372. Academic Press, New York.

Grau, E. G., and Stetson, M. (1977). Pituitary autotransplants in Fundulus heteroclitus: Effect on thyroid function. Gen. Comp. Endocrinol. 32, $427-431$.

Grau, E. G., and Stetson, M. (1978). Dopaminergic neurons and TSH release in Fundulus heteroclitus. Amer. Zool. 18, 651.

Idler, D., and Ng, T. (1983). Teleost gonadotropins: Isolation, biochemistry, and function. In "Fish
Physiology" (W. S. Hoar, D. J. Randall, and E. M. Donaldson, Eds.), Vol. 9, Part A, pp. 187-222. Academic Press, New York.

Jalabert, B.; Breton, B., and Billard, R. (1974). Dosage biologique des hormones gonadotropes des poissons par le test de maturation in vitro des ovocytes de Truite. Ann. Biol. Anim. Biochem. Biophys. 14, 217-228.

Jamaluddin, M., Chakraborti, P., and Bhattacharya, S. (1983). Hormonal regulation of plasma thyroxine level in a murrel Channa punctatus (Bloch). Indian J. Exp. Biol. 21, 386-389.

Kagawa, H., Young, G., and Nagahama, Y. (1983). Changes in plasma steroid hormone levels during gonadal maturation in female goldfish, Carassius auratus. Bull. Japan. Soc. Sci. Fish. 49, $1783-1787$.

Kagawa, H., Young, G., and Nagahama, Y. (1984). In vitro estradiol-17 $\beta$ and testosterone production by ovarian follicles of the goldfish, Carassius auratus. Gen. Comp. Endocrinol. 54, 139-143.

Leatherland, J. (1982). Environmental physiology of the teleostean thyroid gland: A review. Environ. Biol. Fish 7, 83-110.

MacKenzie, D. S. (1982). Stimulation of the thyroid gland of a teleost fish, Gillichthys mirabilis, by tetrapod pituitary glycoprotein hormones. Comp. Biochem. Physiol. A 72, 477-482.

MacKenzie, D. S., and Licht, P. (1984). Studies on the specificity of thyroid response to pituitary glycoprotein hormones. Gen. Comp. Endocrinol. 56, 156-166.

MacKenzie, D. S., Licht, P., and Papkoff, H. (1978). Thyrotropin from amphibian (Rana catesbeiana) pituitaries and evidence for heterothyrotropic activity of bullfrog luteinizing hormone in reptiles. Gen. Comp. Endocrinol. 36, 566-574.

Milne, R., and Leatherland, J. (1980). Changes in plasma thyroid hormones following administration of exogenous pituitary hormones and steroid hormones to rainbow trout. Comp. Biochem. Physiol. A 66, 679-686.

Morley, J. (1981). Neuroendocrine control of thyrotropin secretion. Endocrine Rev. 2, 396-436.

Peter, R. (1970). Hypothalamic control of thyroid gland activity and gonadal activity in the goldfish, Carassius auratus. Gen. Comp. Endocrinol. 14, 334-356.

Peter, R. (1981). Gonadotropin secretion during reproductive cycles in teleosts: Influences of environmental factors. Gen. Comp. Endocrinol. 45, 294-305.

Peter, R. (1983). Evolution of neurohormonal regulation of reproduction in lower vertebrates. Amer. Zool. 23, 685-695.

Peter, R., Chang, J., Nahorniak, C., Omeljaniuk, R., Sokolowska, M., Shih, S., and Billard, R. (1986). 
Interactions of catecholamines and GnRH in regulation of gonadotropin secretion in teleost fish. Rec. Prog. Horm. Res. 42, 513-548.

Peter, R., and Gill, V. (1975). A stereotaxic atlas and technique for forebrain nuclei of the goldfish, Carassius auratus. J. Comp. Neurol. 159, 69-102.

Peter, R., Kah, O., Paulencu, C., Cook, H., and Kyle, A. (1980). Brain lesions and short-term endocrine effects of monosodium L-glutamate in goldfish, Carassius auratus. Cell Tissue Res. 212, $429-442$.

Peter, R., and McKeown, B. (1975). Hypothalamic control of prolactin and thyrotropin secretion in teleosts, with special reference to recent studies on goldfish. Gen. Comp. Endocrinol. 25, 153-165.

Peter, R., Nahorniak, C., Chang, J., and Crim, L. (1984a). Gonadotropin release from the pars distalis of goldfish, Carassius auratus, transplanted beside the brain or into the brain ventricles: Additional evidence for gonadotropin-release-inhibitory factor. Gen. Comp. Endocrinol. 55, 337-346.

Peter, R., Sokolowska, M., Truscott, B., Walsh, J., and Idler, D. (1984b). Secretion of progestogens during induced ovulation in goldfish. Can. J. Zool. 62, 1946-1949.

Peter, R., and Paulencu, C. (1980). Involvement of the preoptic region in gonadotropin release-inhibition in goldfish, Carassius auratus. Neuroendocrinology 31, 133-141.
Peter, R. E., Paulencu, C. R., and Breton, B. (1983). Temporal responsiveness of the ovary of the goldfish to gonadotropin. J. Interdiscip. Cycle Res. 13, 229-239.

Pickford, G., Knight, W., Knight, J., Gallardo, R., and Baker, B. (1981). Long-term effects of hypothalamic lesions on the pituitary and its target organs in the killifish Fundulus heteroclitus. 1. Effects on the gonads, thyroid, and growth. J. Exp. Zool. 217, 341-351.

Sokolowska, M., Peter, R., Nahorniak, C., and Chang, J. (1985). Seasonal effects of pimozide and des Gly ${ }^{10}$ [D-Ala ${ }^{6}$ LH-RH ethylamide on gonadotropin secretion in goldfish. Gen. Comp. Endocrinol. 57, 472-479.

Specker, J., Distefano, J., Grau, E., Nishioka, R., and Bern, H. (1984). Development-associated changes in thyroxine kinetics in juvenile salmon. Endocrinology 115, 399-406.

Stacey, N., MacKenzie, D., Marchant, T., Kyle, A., and Peter, R. (1984). Endocrine changes during natural spawning in the white sucker, Catostomus commersoni. Gen. Comp. Endocrinol. 56, $333-348$.

Yaron, Z., and Barton, C. (1980). Stimulation of estradiol-17 $\beta$ output from isolated ovarian fragments of the plaice Pleuronectes platessa by homologous pituitary extract. Gen. Comp. Endocrinol. 42, 151-154. 